\title{
El pescado como alimento en el Perú virreinal
}

\author{
César Coloma Porcari \\ Presidente del Instituto Latinoamericano de Cultura y Desarrollo \\ sillardearequipa@gmail.com \\ Lima-Perú
}

\section{Resumen}

En este trabajo de investigación se ofrece información documentada sobre el consumo humano de pescado en el Perú virreinal, recogiéndose lo registrado por don Ricardo Palma en sus Tradiciones, así como por Juan de Arona (Pedro Paz Soldán y Unanue), el Dr. Ernst W. Middendorff y fray Bernabé Cobo (1653). La relación de pescados está ordenada alfabéticamente, y se señala si se consumían frescos, secos o salados, según lo indican estos autores.

Palabras clave: Consumo humano de pescado, Historia de la culinaria peruana, peces del Perú, tradiciones, Ricardo Palma, Juan de Arona, Ernst W. Middendorff, Bernabé Cobo.

\section{Abstract}

This research work offers documented information on the human consumption of fish in viceregal Peru, collecting what is recorded by Ricardo Palma in his Traditions, as well as by Juan de Arona (Pedro Paz Soldán y Unánue), Dr. Ernst W. Middendorff and Fray Bernabé Cobo (1653). The list of fish is ordered alphabetically, and it is indicated whether they were consumed fresh, dried or salted, as indicated by these authors.

Keywords: Human consumption of fish, History of Peruvian cuisine, Peruvian fish, traditions, Ricardo Palma, Juan de Arona, Ernst W. Middendorff, Bernabé Cobo. 


\section{César Coloma Porcari (Perú)}

Presidente del Instituto Latinoamericano de Cultura y Desarrollo, Miembro de Número del Instituto Ricardo Palma, Miembro del Centro de Estudios Históricos Militares del Perú. 
El Perú es uno de los principales países pesqueros del mundo y, por ello, todos debemos conocer cuáles eran las especies marinas que se pescaban para el consumo humano en siglos anteriores. De esta manera podemos comprobar cuáles eran las más abundantes y las más apreciadas por los consumidores.

Don Ricardo Palma, en su tradición «El ahijado de la Providencia», recuerda que

Por los años de 1560, daba, en Arequipa, motivo a popular alboroto, la venta de pescado fresco en la recova o plaza de abasto. Esto se explica teniendo en consideración la distancia que hay de la ciudad al mar, así como la escasez de pesca en esa costa (1968, p. 157)

Y agrega que «Aunque no a precio tan fabuloso como en Potosí, donde un róbalo se pagó en miles de duros, el pescado se vendía en Arequipa bastante caro para que solo fuese plato de ricos» (ibid.).

Además, en sus Anales de la Inquisición se refiere a un sujeto que iba a ser quemado vivo por ser judío, el cual celebraba el sábado «cantando salmodias, comiendo pescado guisado con aceite y pan sin levadura» (1968, p. 1215). Y en «Sastre y sisón, dos parecen y uno son» recuerda el dicho «pez chico no come a peje grande» (p. 45).

Asimismo, en «La victoria de las camaroneras» (p. 530), señala que la calle de la Pescadería, que da al Palacio de Gobierno, se llama así porque allí se vendía pescado. Y cuenta del gran pleito que se produjo entre las vendedoras de camarones y las de pescado. En «Nadie se muere hasta que Dios quiere» (p. 823), menciona a las «indias pescadoras que venían de Chorrillos». Además, en «iA nadar, peces!» se refiere a «una garrafa con pececitos del río», la cual fue arrojada por un fraile, 
que gritó «iA nadar, peces!». También recuerda las magníficas representaciones en oro y plata hechas por los antiguos peruanos, en su tradición «El Peje Chico» (pp. 192-196).

Recogemos, asimismo, el testimonio de un personaje tan erudito como lo fue el sacerdote español fray Bernabé Cobo, de la Compañía de Jesús, quien vivió muchos años en el Virreinato del Perú, y que en el año 1653 terminó de escribir su notable Historia del Nuevo Mundo, publicada en Sevilla por don Marcos Jiménez de la Espada, en cuatro volúmenes (1890-1893) y reeditada en la Biblioteca de Autores Españoles en Madrid en 1956.

Como complemento, incorporamos la información que ofrece el Dr. Ernst Middendorf, importante científico alemán que vivió muchos años en nuestro país y que publicó Perú. Beobachtungen und Studien über das Land und seine Bewohner (Berlín, 1893), obra traducida al castellano y publicada por la Universidad Nacional Mayor de San Marcos en 1973.

También citamos las tres menciones al pescado como alimento humano que hace Juan de Arona, pseudónimo de Pedro Paz Soldán y Unanue, en su Diccionario de peruanismos de 1882. Estas son las siguientes: su comentario sobre el uso del término «pescado» en el Perú, en el que recuerda que «La palabra pez no existe en nuestra conversación» (pp. 395-396); su festivo poema referente a nuestro plato nacional, el «seviche», elaborado inicialmente con pescado, naranja agria y ají, sin limón ni cebolla: «iQueréis que mi musa cante / O por lo menos decante, / En un oportuno espiche, / las delicias del picante / y del peruano seviche?» (pp. 398 y 464); y por último su mención al pez llamado «suche», que veremos más adelante.

Los nombres científicos los hemos tomado de la obra Los peces del Perú, del naturalista norteamericano Dr. Henry W. Fowler, 
miembro de la Academia de Ciencias Naturales de Filadelfia, y que fuera publicada por la Universidad Nacional Mayor de San Marcos en 1945.

Asimismo, hemos recurrido al Nuevo manual de la cocina peruana escrito en forma de diccionario por un limeño mazamorrero, publicado en Lima por la famosa Casa Rosay en 1926, donde encontramos dos recetas para la preparación de las anchovetas (tanto frescas como secas y saladas). Curiosamente, más de dos siglos después de que el padre Cobo (1653) registrara que en su tiempo se consumían las anchovetas frescas y saladas (aunque el fraile no ofrece ninguna receta), continuaban comiéndose de esa manera en Lima.

Quienes investigan la historia de la alimentación en el Perú podrán descubrir en el presente ensayo cuáles eran los peces que se empleaban para el consumo humano. Asimismo, encontrarán, en algunos casos, la indicación de si se comían frescos y asados, o secos y salados. Lamentablemente, el padre Cobo no ofrece ninguna receta y, por cierto, no se refiere a ningún plato criollo que conocemos en la actualidad. Con el fin de evitar errores cabe advertir que cuando este autor califica a un pescado de «regalado» lo hace como sinónimo de delicado y exquisito.

Por último, recordamos que nuestro primer trabajo de investigación sobre el consumo humano de pescado en el Perú (según el padre Bernabé Cobo), lo publicamos el año 2000. Allí ya ofrecíamos información documentada sobre las especies marinas que en tiempos pasados eran muy estimadas como alimento, inclusive las que actualmente se desprecian, como las anchovetas.

Incluimos en este trabajo nuevos datos recopilados posteriormente. Ofrecemos la información sobre los peces en orden alfabético e incluimos sus nombres científicos y la familia 
a la que pertenecen, facilitándose así su consulta, en lugares en donde los nombres vulgares sean distintos. Todas las referencias a Ricardo Palma, Bernabé Cobo, Ernst Middendorf y al manual de cocina de la casa Rosay corresponden a las ediciones ya citadas, salvo referencia expresa a otros textos. La relación es la siguiente:

Aguja.- Belone exilis stolzmanni Steindachner; fam. Belonidæ.

Fray Bernabé Cobo se refiere al pez aguja, indicando que

Dos diferencias de agujas he visto en esta mar del Sur, unas largas dos o tres palmos, y otras pequeñas de solo un palmo, del tamaño de pejerreyes; y las unas y las otras tienen la cabeza larga y la boca o (sic) hocico largo como pico de ave $[\ldots]$, y así las grandes como las pequeñas son de buen sustento (p. 306).

En el siglo XIX, el Dr. Ernst W. Middendorf registra que «Los pescados que rara vez son traídos al mercado, son [..] la "aguja", es una especie de anchoa» (p. 406).

Anchoveta.- Engraulis ringens Jenyns; fam. Engraulidæ.

Don Ricardo Palma, en su tradición «Rudamente, pulidamente, mañosamente», se refiere a las anchovetas. Allí, al tratar sobre un personaje, dice: «iQué fortuna la de las anchovetas! En vez de ir al puchero, se las deja tranquilamente en el agua» (1968, p. 646). Asimismo, en su tradición «Contra pereza, diligencia», socarronamente afirma que San Pedro era un «plebeyote pescador de anchovetas» (p. 1091). Y en «Lluvia de cuernos» cuenta que un personaje era «pescador de anchovetas en agua mansa» (389). 
Antaño había estafadores que hacían pasar las anchovetas (más baratas) por sardinas (más costosas). En «Una moza de rompe y raja», Palma cuenta que el pueblo culpaba a José de San Martín por la emisión de papel moneda; agrega que el pueblo «la da siempre de malicioso y de no tragar anchoveta por sardina» ( $\mathrm{p}$. 1969).

El padre Cobo, al referirse a este pez, afirma que

No es menor la copia que hay de anchovetas [...] las cuales también algunas veces, por su multitud, varan en tierra y se quedan en seco, particularmente cuando son perseguidas por peces grandes; y cuando así dan en tierra, suele quedar un gran camellón déllas a lo largo de la playa, como yo lo ví una vez, que no fue posible agotarlas. (p. 299)

\section{Agrega que}

Suelen venir por esta costa del Perú tan espesos cardúmenes de anchovetas, que, navegando yo de Lima a Trujillo el año 1627, nos cercó el navío uno tan grande, que parecía una mancha negra el agua, y por estar a la sazón en calma, las cogía la gente del navío a canastos, con no más trabajo que meter los canastos de canto en la mar y sacarlos llenos de anchovetas. (ibíd.).

Recuerda además que

En esta ciudad de Lima y en su comarca se gasta todo el año gran cantidad de anchovetas frescas, y se tiene por pescado regalado y de muy buen sabor; fuera de que es gran socorro para la gente pobre, porque con un real de anchovetas cena toda la gente de una casa, aunque sean diez o doce personas. (p. 300). 
Y agrega que

Cuando veo tan grande inmensidad de anchovetas en esta mar del Sur, vengo a sentir que así como crió Dios la hierba en los campos para pasto de animales terrestres, así también crió las anchovetas en la mar para sustento de los acuátiles; porque todo género de pescado mayor y menor, con otra infinidad de aves marinas, se mantienen déllas; y los pescadores no ponen de ordinario en los anzuelos otra carnada o cebo que de anchovetas, para pescar todo género de peces (p. 300).

y algo muy importante: «También se secan muchas al sol y se llevan a varias partes» (ibíd.).

Asimismo, hemos descubierto dos antiguas recetas para la preparación de las anchovetas, tanto las frescas como las secas y saladas que menciona fray Bernabé Cobo (Coloma, 2010). Estas se encuentran en la obra Nuevo manual de la cocina peruana escrito en forma de diccionario por un limeño mazamorrero y son las siguientes:

Anchovetas.- Estos pescaditos, que con tanta profusión se expenden en todos los mercados de la costa, se comen cuando son frescos, echándolos a freír en manteca, con un poco de sal, hasta que se tuesten; si son secos y salados, se les lava en agua caliente y luego se les pone a freír en aceite de olivo (sic) con un poco de ajos enteros, aderezándolos después con el mismo aceite, cebolla cruda a rajitas y un poco de vinagre blanco (Rosay, 1926, pp. 10-11).

Atún.- Thunnus albacares Bonnaterre; fam. Scombridæ.

Afirma fray Bernabé Cobo en 1653 que

El verdadero atún no se halla en toda esta mar del Sur más que en la costa del reino de Chile, de donde lo suelen traer 
salado a esta ciudad de Lima. Dícese que a tiempos suben estos atunes a desovar al estrecho de Magallanes, y que a esa causa se hallan solamente en la costa de Chile (p. 310-311).

El fraile nos informa que en su época (siglo XVII) se vendía el pez espada salado como si fuera atún, engañando así a los consumidores (ibíd.).

Ayanque o cachema.- Cynoscion analis Jenyns; fam. Sciænidæ.

Don Ricardo Palma menciona este pez en «El poeta de las adivinanzas» ( p. 712). Allí se refiere a don Esteban de Terralla y Landa, quien con el pseudónimo de Simón Ayanque escribió Lima por dentro y fuera. En 1653, el padre Cobo registró que «El ayanque es propio destas Indias, de dos palmos de largo, poco más o menos; tiene la boca grande y colorada y agudos dientes, y se cuenta entre los pescados regalados» (p. 303). El Dr. Middendorf, por su parte, en el siglo XIX, indica que «El "ayanque” es un pez pequeño, parecido al pámpano, aunque mucho menos tierno» (p. 406).

Bagre.-Arius multiradiatus Günther; fam. Ariidæ

Don Ricardo Palma, en su tradición «Don Tadeo López, el condecorado», recoge «una graciosa silva» del festivo poeta fray José Joaquín de Larriva: «Canto tu cara torva y de vinagre, / tus cortos brazos y tu cuerpo tieso; / canto tu boca, que es boca de bagre, / tus ojos tuertos y nariz sin hueso» (p. 886). Y en «Los Barbones» (p. 443), se refiere a «una pescadora de bagres y camarones», mientras que en «La victoria de las camaroneras» (p. 530), cuenta que la calle de la Pescadería, de Lima, lleva 
su nombre por los «pescadores de bagres» que vendían allí sus productos (ibíd.)

Asimismo, en Neologismos y americanismos, registra: «Bagre.- Pez que se encuentra en algunos ríos de América. Figuradamente se aplica este nombre a la mujer fea y despreciable»(1896, pp. 20-21), y en Papeletas lexicográficas anota: «Bagre.- Pequeño pez que se encuentra en muchos ríos de América. Figuradamente decimos -es un bagre- por la mujer fea y despreciable», y agrega: «Bagrero.- El que con frecuencia enamora mujeres feas y sin mérito» (1903, p. 29).

Afirma el padre Cobo que los bagres

Críanse en la mar y en ríos y lagunas; los de la mar son largos como una tercia; mátanse muchos en el puerto del Callao. Mas los de agua dulce son tenidos por manjar más regalado y se diferencian mucho en grandeza, porque los menores son de un palmo, y de aquí van creciendo [...] [aunque] Los menores y medianos son de más sano mantenimiento y más sabrosos (pp. 300-301, agregado nuestro)

Bonito.- Sarda chiliensis Cuvier; fam. Scombridæ.

Para fray Bernabé Cobo, el bonito, caballa, sierra y jurel son un

manjar grosero y de poca estima, y que no suelen comerlo sino a falta de otro más regalado y sano; y con todo eso son muy sabrosos al gusto, particularmente el bonito, y más si está salpresado, que entonces se parece al atún en el sabor (p. 305). 
Agrega que

Críanse copiosamente todos estos pescados en esta mar del Sur, y apenas hay día que no los pesquen en el puerto del Callao; y cuando acude algún cardumen de bonitos, que es muy frecuentemente, son innumerables los que se matan; $\mathrm{y}$ suelen venderse tan baratos, que dan dos o tres al real, y cuando más caros valen a real o dos reales cada uno (ibíd.)

El Dr. Middendorf afirma lo siguiente: «El "bonito", llamado así por su hermoso brillo azul, es un pescado ordinario, de carne de color algo oscuro y seca» (p. 406).

Caballa.- Pneumatophorus peruanus Jordan \& Hubbs; fam. Scombridæ.

La caballa, el bonito, la sierra y el jurel, según fray Bernabé Cobo, son un «manjar grosero y de poca estima, y que no suelen comerlo sino a falta de otro más regalado y sano; y con todo eso son muy sabrosos al gusto» (p. 305).

\section{Además}

Las caballas son tan comunes en esta costa y puerto del Callao como los bonitos. Suelen venir a menudo grandes cardúmenes, y con la abundancia bajan tanto de precio, que las he visto yo vender en el Callao veinticinco al real [...] de la caballa hacen los pescadores carnada para pescar otros peces (ibíd.).

Cabinza.- Isacia conceptionis Cuvier; fam. Pomadasyidæ.

Fray Bernabé Cobo ofrece una información muy breve sobre el pescado llamado cabinza: «críanse con 
abundancia en esta Mar del Sur; adonde también se hallan cavinzas de un jeme y más de largo, a las cuales en España llaman chopas» (p. 302).

Cabrilla.- Paralabrax humeralis Valenciennes; fam. Serranidæ.

Escribe fray Bernabé Cobo que

La cabrilla es pescado propio de las Indias y muy regalado: parécese mucho a la trucha y solamente se cría en la mar. Tiene un palmo y más de largo; todo él está lleno de unas pintas rojas. Mátanse muchas cabrillas en el puerto del Callao, y déllas goza en abundancia esta ciudad de Lima (p. 302).

El Dr. Middendorf afirma que «Los pescados que rara vez son traídos al mercado, son: [...] La "cabrilla", pequeño y lindo pez con manchas rojas» (p. 406).

Cachema.- vide Ayanque.

Cazón.- vide Tollo.

Chita o sargo.- Anisotremus scapularis Tschudi; fam. Pomadasydæ.

Fray Bernabé Cobo apreciaba mucho este pescado y afirmó que «La chita es pescado muy regalado, de que hay mucho en las Indias y se mata gran copia en el puerto del Callao; es el pescado que en España llaman sargo» (p. 308). En el siglo XIX el Dr. Middendorf registra que «Los pescados que rara vez son traídos al mercado, son: La "chita", pez pequeño, que sólo se come frito» (p. 406). 
Coco o suco.- Polyclemus peruanus Steindachner; fam. Sciænidæ.

Sobre este pez, apreciado en el siglo XVII, encontramos que fray Bernabé Cobo afirma que «El pescado que llaman coco en la costa deste reino es un poco menor que la corvina y de tan buena comida como ella» (p. 308).

Cojinova.- Seriolella crassus Starks; fam. Carangidæ.

Fray Bernabé Cobo registra únicamente que «La coginoa (sic) es un pescado muy parecido a la palometa» (p. 303). Y el Dr. Middendorf señala que «Los pescados que rara vez son traídos al mercado, son: [...] La "cojinova", pez con manchas negras, cuya carne se parece a la de corvina, pero no es tan suave» (p. 406).

Congrio.- Genypterus maculatus Tschudi; fam. Ophidiidæ.

Fray Bernabé Cobo afirma que

El congrio no es tan común como los dos referidos [róbalo y mero], porque no se halla igualmente en todas las costas desta mar del Sur; donde mayor cantidad se pesca es en la costa de la diócesis de Arequipa y particularmente en el puerto de Arica, de donde se lleva salado la tierra adentro, $\mathrm{y}$ donde quiera es de los mejores pescados salados que se comen, tanto que se suele hacer dél manjar blanco (p. 306).

Se debe aclarar que en este caso el plato que llama «manjar blanco» era salado y no dulce.

Corvina.- Cilus gilberti Abbott; fam. Sciænidæ. 
Don Ricardo Palma, en su tradición «El ahijado de la Providencia», cuenta que «Una mañana, en la Cuaresma de ese año [1560], presentóse en la plaza un pescador con un cesto de corvinas, las que a poco rato hallaron compradores que pagaron sin regatear» (p. 158). Pero ocurrió que «Quedaba la última, y disputábanse la posesión de ella un fraile dominico» y un conquistador. Este sacerdote, aprovechando su condición de tal, «echando mano a la corvina», se atrevió a abofetear al conquistador. Este sacó su espada, la cual partió con su pie, $y$

ijuicios misteriosos de Dios!, el pedazo de la punta rebotó, clavándose en el antebrazo del dominico, que, olvidando la mansedumbre a que por sus votos y condición estaba obligado, se dejó arrebatar de la ira hasta el punto de abofetear a un honrado y respetable anciano (p. 158).

Asimismo, en su tradición «Un predicador de lujo», al referirse a los pescadores del puerto de Huacho, cuenta que estos «vendían gato por liebre» y que hasta «transformaban un róbalo en corvina» (p. 789).

Afirma fray Bernabé Cobo que «Corvinas se hallan en todas partes; son largas de dos a tres palmos y de buen mantenimiento» (p. 308). El Dr. Middendorf indica que «La "corvina" es el pescado de mayor consumo, su carne es muy sabrosa y tierna, a no ser que provenga de peces muy viejos. Nunca falta en el mercado» (p. 406).

Jurel.- Trachurus murphyi Nichols; fam. Carangidæ.

El jurel, el bonito, la caballa y la sierra son, para fray Bernabé Cobo, un «manjar grosero y de poca estima, y que no suelen comerlo sino a falta de otro más regalado 
y sano; y con todo eso son muy sabrosos al gusto» (p. 305).

Lenguado.- Paralichthys adspersus Steindachner; fam. Bothidæ.

Don Ricardo Palma, en su tradición «Sastre y sisón, dos parecen y uno son» se refiere a un personaje que fue encarcelado con la siguiente expresión: «En el mar los lenguados, y en chirona los deslenguados» (p. 44).

Fray Bernabé Cobo dice que

Estos tres géneros de pescados [pámpano, sierra de Paita y lenguado] son los mejores que se comen en todas las Indias, y particularmente en la ciudad de Lima, donde nunca faltan en todo el año, aunque no en tanta abundancia como otros, sino es que, porque todos los apetecen como manjar regalado (p. 304).

Además,

En todas las costas de la Indias se crían lenguados grandes y pequeños; unos son no mayores que medio palmo; otros se hallan que tienen a tres y a cuatro palmos, y algunos que pesan diez o doce libras; son muy anchos y de poco canto; diferéncianse algo de los de España; pero chicos y grandes son estimados, porque se tienen por mantenimiento sano y regalado (ibíd.).

Y «Mátanse muchos en el puerto del Callao alrededor de la isla [de San Lorenzo], porque siempre andan entre peñas y escollos» (ibíd.).

Lisa o liza.- Mugil cephalus Linnæus; fam. Mugilidæ. 
Afirma fray Bernabé Cobo que

Las lizas son las que llaman albures en España; críanse muchas, así en el mar como en muchos ríos [...]; es el pescado más sabroso que se come en las Indias, pero no el más sano. Hay lizas grandes y pequeñas; las más crecidas tienen a dos palmos de largo (p. 308).

Lo mismo se afirma en el siglo XIX: «La "lisa", un pescado fino semejante a la corvina (sic), es preferida por mucho a ésta, ya que su carne es igualmente blanca y más tierna» (Middendorf, 1973 [1893], p. 406).

Lorna.- Sciæna deliciosa Tschudi; fam. Sciænidæ.

Sobre este pescado, fray Bernabé Cobo anota únicamente que «La lozna (sic) es la que llaman en España cerbal» (sic) (p. 302).

Machete.- Potamalosa notacanthoides Staindachner; fam. Clupeidæ.

Escribe fray Bernabé Cobo sobre «machuelos y machetes, que casi son una misma cosa. Al machuelo nombran en España lacha; es del largor de un palmo y tiene muchas espinas. El machete es un poco mayor» (ibíd.). El Dr. Middendorf recuerda que «Los pescados que rara vez son traídos al mercado, son: [...] El "machete", así llamado por su forma chata y filuda, un pescado ordinario con muchas pequeñas espinas» (p. 406).

Mero.-Mycteroperca xenarcha Jordan; fam. Serranidæ.

Don Ricardo Palma, en su tradición «Quizá quiero, quizá no quiero», recuerda a Quevedo: «de las carnes el 
carnero, / de los pescados el mero, / de las aves la perdiz / y de las mujeres la Beatriz» (p. 37). Sobre este pez, fray Bernabé Cobo escribe lo siguiente:

El mero, aunque se cría en esta mar del Sur con abundancia, no se tiene dél la estimación que en otras partes, conforme al refrán que dice: de los pescados el mero, por haber otros muchos que se le prefieren; con todo eso, se mata y gasta buena cantidad dello. Son los meros de ordinario menores que los róbalos, y suelen tener desde dos hasta cuatro palmos de largo. (p. 306).

Mojarra.-Eucinostomus californiensis Gill; fam. Gerreidæ.

Fray Bernabé Cobo afirma que «También son más frecuentes las mojarras en la América septentrional que en esta austral, dado que las hay en toda esta costa del Perú, donde no se estiman mucho, por haber abundancia de otros pescados mayores» (p. 302).

Ojo de uva.- Hemilutjanus macrophthalmos Tschudi; fam. Serranidæ.

Registra fray Bernabé Cobo que «El pescado llamado ojo de uva, porque tiene los ojos grandes, se parece a la chita; es de palmo y medio de largo, a quien llaman en España monje» (p. 308).

Pámpano.-Trachinotus paitensis Cuvier; fam. Carangidæ.

Afirma fray Bernabé Cobo que

Estos tres géneros de pescados [pámpano, sierra de Paita y lenguado] son los mejores que se comen en todas las Indias, y particularmente en la ciudad de Lima, donde nunca faltan en todo el año $[\ldots]$ porque todos los apetecen como manjar regalado (p. 304) 
y que «Los pámpanos se crían en ambos mares del Norte y del Sur, y en la costa deste arzobispado de Lima se mata buena cantidad dellos» (ibíd.). Cobo señala además que

Es el pámpano comúnmente largo una tercia, si bien se hallan otros mucho menores y otros que tienen a dos palmos y más; son muy anchos en proporción de su longitud y delgados, de carne muy blanda, blanca y delicada, y comidos asados frescos, son de gran regalo (ibíd.).

Además, Middendorf señala que

En pescado el mercado ofrece más de 20 variedades, casi todas de mar y muchos de sabor exquisito. En primer lugar debe mencionarse el "pámpano", un pez bastante pequeño, de más de un pie de largo, ancho y chato, de carne extraordinariamente fina. A veces lo traen en grandes cantidades al mercado, pero otras faltan completamente, durante largo tiempo (p. 406).

Pargo.- Lutjanus jordani Gilbert; fam. Lutjanidæ.

Fray Bernabé Cobo afirma que es «de comida sana y regalada» (p. 306) y que, además, «El pargo es pescado en lo exterior colorado, desde uno hasta dos palmos de largo y de cuerpo grueso; críase poco en esta mar del Sur» (ibíd.).

Peje-blanco.- Caulolatilus cabezon Evermann \& Radcliffe; fam. Latilidæ.

Afirma fray Bernabé Cobo que

En toda esta costa del Perú, y en especial en el puerto del Callao, se mata mucho peje-blanco, de que hay todo el año 
grande abundancia y se estima por pescado regalado. Es largo una tercia, poco más o menos, y dale nombre su color, que es un blanco que tira a leonado, si bien su carne es muy blanca (p. 300).

Peje gallo.- Callorhynchus callorynchus Linnæus; fam. Callorhynchidæ.

\section{Cuenta fray Bernabé Cobo que}

El peje-gallo es muy hermoso; tiene de largo de dos a tres palmos, cuero muy delicado y de un color plateado y reluciente; sobre la nariz un pico como de gallo, y debajo dél una cresta, y la boca de particular hechura, con unas aletas grandes sobre el vientre, que le nacen de la cabeza, de dos palmos de punta a punta, y otras dos aletas menores abajo del vientre, y una cola que va adelgazando hasta acabar tan delgada en la punta como de ratón, y de una tercia de largo (p. 309).

El Dr. Middendorf dice que «Los pescados que rara vez son traídos al mercado, son: [...] El 'pejegallo', llamado así por su aleta dorsal en forma de cresta» (p. 406).

Pejerrey.- Odontesthes regia regia Humboldt; fam. Atherinidæ.

Don Ricardo Palma, en su tradición «El alacrán de fray Gómez», cuenta que este sacerdote encontró a san Francisco Solano acostado en la enfermería del convento y no quería comer ningún alimento. Ante la insistencia del fraile, el santo le dijo «solo comería con gusto un par de pejerreyes» (p. 210). Y «Fray Gómez metió la mano derecha dentro de la manga izquierda, y sacó un par de pejerreyes tan fresquitos que parecían acabados de salir 
del mar» (ibíd.). Y le dijo al santo «Voy a guisarlos. Y ello es que con los benditos pejerreyes quedó san Francisco curado como por ensalmo» (ibíd.).

Fray Bernabé Cobo afirma que

Así en la mar como en los ríos desta costa del Perú, y en algunas lagunas mediterráneas se crían abundantemente los pejereyes, y de cualquiera manera que sean se tienen por pescado tan sano, que se permite comerlo a los enfermos, pero los pejereyes de la mar son preferidos en sanidad a los de agua dulce, comoquiera que los de los ríos son más sabrosos. Los que se crían en la mar son generalmente de un tamaño no mayor de un palmo de largo, poco más o menos. Y mátanse muchos todo el año en las costas de las diócesis de Lima y Arequipa, y es cosa que admira ver la gran copia dellos que se cogen en el puerto de Quilca, de la diócesis de Arequipa; y a veces acuden en tanta cantidad en el puerto del Callao, que suelen varar en tierra y los cogen a mano (p. 300).

Además, cuenta fray Bernabé que

En los pejereyes de agua dulce se halla muy grande variedad en su grandeza: los menores de todos son los que se crían en la laguna de Chucuito [lago Titicaca], diócesis de Chuquiabo [La Paz], los cuales apenas tienen de largo medio jeme; en los ríos desta costa se hallan muy crecidos, como son los ríos de Valdivia [reino de Chile], de Camaná, de Cañete y otros; donde se prenden tan grandes pejereyes, que tienen a dos palmos y más de largo, y gruesos en proporción, los cuales son de muy sabroso y regalado gusto (ibíd.).

En el siglo XIX el Dr. Middendorf afirma que «El "pejerrey" es un pez de mar, parecido a la trucha, 
de un pie de largo, delgado, de color verde gris, muy sabroso» (p. 406), aunque «El 'pejerrey', de agua dulce, se parece en su aspecto a nuestra trucha, aunque no es tan sabroso» (ibíd.).

Peje-sapo.- Sicyases sanguineus Müller \& Troschel; fam. Gobiesocidæ.

El erudito fray Bernabé Cobo cuenta que «El peje-sapo es parecido en el tamaño y figura al sapo, por lo cual le dan este nombre» (p. 303).

Pez espada.- Xiphias gladius Linnæus; fam. Xiphiidæ.

Sobre el pez espada, fray Bernabé Cobo afirma que «El peje-espada es de la grandeza de un buen becerro, y puesto caso que no sea el mayor de la mar, a lo menos es el más fuerte y bravo que se conoce en el agua» (p. 310). Agrega que

Críanse en todos los mares de las Indias del Norte y del Sur, y mátanse muchos en el puerto de Payta. Su carne fresca es comida regalada, y mucho más echada en salmuera, porque suple la falta del atún, y se lleva deste pescado así salado muchas botijas a todas partes y pasa plaza de atún, y tal nombre le dan dondequiera (ibíd.).

Pintadilla.- Cheilodactylus variegatus Valenciennes; fam. Cheilodactylidæ.

Sobre este pescado fray Bernabé Cobo afirma que «Pintadillas llaman a ciertos pescados que son anchos y de palmo y medio de largo, de dura escama» (p. 303).

Raya.- Psammobactis lima Poeppig; fam. Rajidæ. 
El erudito fray Bernabé Cobo registra que «Rayas grandes y chicas se hayan mucho en todas partes, así en la mar como en algunos ríos» (ibíd.). El Dr. Middendorf, en el siglo XIX, afirma que «La "raya" $[\ldots]$ solo raras veces se pesca» (p. 406).

Róbalo.- Sciæna starksi Evermann \& Radcliffe; familia Sciænidæ.

Don Ricardo Palma, en su tradición «El ahijado de la Providencia», recuerda que en Arequipa por el año 1560 el pescado fresco se vendía a precios muy altos y agrega: «Aunque no a precio tan fabuloso como en Potosí, donde un róbalo se pagó en miles de duros, el pescado se vendía en Arequipa bastante caro para que solo fuese plato de ricos» (p. 157). Asimismo, en su tradición «Un predicador de lujo», al referirse a los pescadores del puerto de Huacho, cuenta que estos «vendían gato por liebre» y que hasta «transformaban un róbalo en corvina» (p. 789).

Para fray Bernabé Cobo, el róbalo es «de comida sana y regalada», y que

Mátanse tantos róbalos en la costa deste arzobispado de Lima, que apenas hay día que los pescadores del puerto del Callao dejen de traer algunos, y no pocas veces que topan con algún cardumen, vienen cargados déllos. Háylos pequeños y grandes, desde una tercia hasta dos palmos los primeros, y los segundos, desde una hasta dos varas de largo; y róbalo he visto yo que no podía un hombre levantarlo del suelo y fue menester que lo llevaran dos atravesado en una pértiga (p. 306). 
Agrega que «lo que tiene bueno este pescado, que la carne del pequeño y del grande es de igual bondad y tan blanca como pechugas de ave» (ibíd.). En 1893 el Dr. Middendorf afirma que «El "róbalo" es una clase de corvina grande, pesa de 25 a 30 libras y su carne es blanca, aunque un poco dura y seca» (p. 406).

Sardina.-Sardinops sagax sagax Jenyns; familia Clupeidæ.

Don Ricardo Palma, en su tradición «Vítores», al referirse a la disputa de las distintas órdenes religiosas por los bienes de los moribundos, dice que «Cada cual arrimaba la brasa a su sardina», «esto es, para el acrecentamiento de los bienes de su comunidad» (p. 299). Había estafadores, antaño, que hacían pasar las anchovetas (más baratas) por sardinas (más costosas). Y Palma, en «Una moza de rompe y raja» (p. 969), cuenta que el pueblo culpaba a José de San Martín por la emisión de papel moneda. Agrega que el pueblo «la da siempre de malicioso y de no tragar anchoveta por sardina» (ibíd.). Asimismo, en «San Antonio del fondo» (p. 1092), menciona a «un fraile franciscano más flaco que esqueleto de sardina» (ibíd.).

En el año 1653, fray Bernabé Cobo registró que «En todas las costas de la mar del Sur desta América Austral se crían sardinas con gran abundancia, señaladamente en las del Arzobispado de Lima, obispado de Arequipa y reino de Chile» (p. 299). Se empleaban para fertilizar los campos, por lo que debían «enterrar sardinas con las semillas que sembraban, para que diesen fruto copioso» (ibíd.), y

fuera muy costoso y difícil este beneficio, si no se hallaran tan a mano y en tanta abundancia las sardinas. Las cuales 
se crían en tanta cantidad en las costas dichas, que la mar suele echar a tierra gran suma déllas, con que los indios estercolaban y fertilizaban las tierras de labor marítimas, y tenían abundancia de pescado con que mantenerse (ibíd.).

Además, en el reino de Chile y en la isla de Chiloé «se aderezan [...] como los arenques de España, donde se traen a esta ciudad de Lima y se estiman por cosa regalada; si bien no son tan grandes como las sardinas arenques (sic) de Europa» (ibíd.). Y en el siglo XIX, el Dr. Middendorf registra que «Los pescados que rara vez son traídos al mercado, son: [...[ Sardinas grandes y pequeñas» (p. 406).

Sargo.- vide Chita.

Sierra.- Scomberomorus sierra Jordan \& Starks; familia Scombridiæ.

La sierra, el bonito, la caballa y el jurel son, para fray Bernabé Cobo (1653), un «manjar grosero y de poca estima, y que no suelen comerlo sino a falta de otro más regalado y sano; y con todo eso son muy sabrosos al gusto» (p. 305), aclarando que, además, «La sierra es muy parecida al bonito, salvo que es menor, más delgada y mejor comida; tiene unas pintas doradas por en medio; y no se matan tantas sierras como caballas y bonitos» (ibíd.).

Fray Bernabé se refiere, también, a un pescado llamado antiguamente «sierra de Payta» (sic), que es diferente de la «sierra» común. Era uno de «los mejores que se comen en todas las Indias, y particularmente en la ciudad de Lima, donde nunca faltan en todo el año [...] porque todos los apetecen como manjar regalado» (p. 304) Además, 
La sierra de Payta es larga de dos a cuatro palmos y delgada; danle este nombre porque se cogen muchas en el puerto de Payta, diócesis de Trujillo; críanse también en todo lo restante desta costa del Perú, y en el puerto del Callao se pescan no pocas; es pescado regalado y que, a juicio de muchos, corre parejas con el pámpano (ibíd.).

\section{Agrega también que}

En hermosura se aventaja a cuantos yo he visto; porque es de un cuero muy delgado, blanco, que parece plateado, y todo él está pintado a hileras de unas manchas pequeñitas amarillas, que no parecen sino estrellas de oro según resplandecen (ibíd.).

Y por último, afirma que «tiene otra particularidad este pescado, y es que, cuanto mayor, es más regalado manjar, cosa que no se halla en otros» (ibíd.).

Suche.- Trichomycterus rivulatus Valenciennes; fam. Trichomycteridæ.

Juan de Arona afirma que «En la laguna de Puno [lago Titicaca] el suche es un pescado de fama» (p. 465). Y fray Bernabé Cobo escribe que

En la provincia del Collao deste reino del Perú se cría en los ríos y en la gran laguna de Chucuito [lago Titicaca] una especie de vagres (sic) que los indios llaman suches; tienen de largo una tercia y también los hay de dos palmos. Es tan mantecoso este pescado que casi todo él se resuelve en grasa. Hállase más de ordinario en las orillas de los ríos y de la laguna sobredicha [lago Titicaca], entre la lama, juncales y maleza, que en las corrientes claras de los ríos y hondo y limpio de la laguna. (p. 301). 
Agrega que

Es sabrosísimo al gusto, particularmente en empanadas, pero comido fresco, no muy sano; por lo cual lo suelen comer de ordinario salpresado. Llévase gran cantidad destos suches salados y secos a otras partes, por ser muy grande la copia que se mata déllos en la dicha provincia del Collao (ibíd.).

Por último,

El unto de suche es muy caliente y medicinal; ablanda los escirros y lobanillos y las demás durezas de hígado y bazo; y echando dél algunas gotas en el oído doloroso por intemperie fría, mitiga el dolor; allende desto, se experimenta del suche que inflama la garganta y causa flemas y llagas (ibíd.).

Tiburón.- vide Tollo o cazón.

Tollo o cazón.- Mustelus dorsalis Gill; familia Triakidæ.

El tollo o cazón es una especie de tiburón (de menor tamaño). Don Ricardo Palma, en su tradición «Un tiburón», cuenta que a un personaje le dijeron «tú tienes más años de tiburón que de servicios» (p. 1097). Y en «Manumisión» (p. 138) afirma que «Los tripulantes negreros eran tratados como piratas, colgados de una antena y arrojados al mar para alimento de tiburones» (ibíd.).

Fray Bernabé Cobo llama «cazón» al tollo y afirma hace tres siglos y medio que «En toda la costa desde reino del Perú se cría gran copia de cazones de todas especies conocidas en España y aún de otras propias de las Indias» (p. 38). Agrega que 
Hay cazones de diferente grandeza; los menores y de más regalada comida son de una tercia o media vara de largo; y de aquí van creciendo hasta hallarse algunos de dos varas que parecen tiburones. De todos estos géneros de cazones se matan en el Callao y se comen frescos en Lima; y dellos y de tiburones se hace gran cantidad de tollo en muchos puertos, particularmente en el de Payta, diócesis de Trujillo, y en el de Guambacho, deste arzobispado de Lima (p. 308).

La carne del tollo y otras especies afines, para su comercialización y consumo, era «salpresada, amojamada, salada y secada al sol, o simplemente oreada como peje-palo» (ibíd.).

Vieja.-Pimelometopon darwini Jenyns; fam. Labridræ.

El jesuita fray Bernabé Cobo escribe en 1653 que «Del mismo tamaño [de la chita] es el pescado llamado vieja, y no inferior en bondad; es colorado y de muchos dientes» (ibíd.).

Es nuestro deseo que estas notas contribuyan a ampliar en algo el conocimiento sobre la historia de la alimentación en el Perú.

\section{Referencias bibliográficas}

Arona, J. de. (1882). Diccionario de peruanismos. Ensayo filológico. Lima: Librería Francesa Científica J. Galland.

Cobo, B. (1956). Historia del Nuevo Mundo (1653), en Biblioteca de Autores Españoles, tomo 91. Madrid: Ediciones Atlas, Gráficas Orbe.

Coloma Porcari, C. (2000). «El consumo de pescado en el Perú virreinal», Espacio, año 21 , № 47. Lima, junio-julio, pp. 102-107. 
. (2010). «El tradicional consumo de anchovetas en Lima». Voces, Revista Cultural de Lima, año 1 1, N 43. Lima, pp. 42-43.

Fowler, H. W. (1945). Los peces del Perú. Catálogo sistemático de los peces que habitan en aguas peruanas. Lima: Museo de Historia Natural Javier Prado, Universidad Nacional Mayor de San Marcos.

Middendorf, E. W. (1893). Peru. Beobachtungen und Studien über das Land und seine Bewohner während eines 25 Jahringen Aufenthalts. T. I. Berlín: Robert Oppenheim (Gustav Schmidt).

. Perú. Observaciones y estudios del país y sus habitantes durante una permanencia de 25 años. T. I. Lima: Universidad Nacional Mayor de San Marcos.

Palma, R. (1968). Tradiciones peruanas completas. Madrid: Aguilar S. A. de Ediciones, Selecciones Gráficas.

Librería de Carlos Prince.

. (1896). Neologismos y americanismos. Lima: Imprenta y . (1903). Papeletas lexicográficas. Lima: Imprenta La Industria.

Rosay, E. (ed.). (1926). Nuevo manual de la cocina peruana escrito en forma de diccionario por un limeño mazamorrero. Lima: Librería Francesa Científica y Casa Editorial E. Rosay.

Recibido el 16 de agosto de 2020 Aceptado el 29 de septiembre del 2020. 